\title{
Psychostimulant-Induced Behavioral Sensitization Depends on Nicotinic Receptor Activation
}

\author{
Anton N. M. Schoffelmeer, Taco J. De Vries, George Wardeh, Henrica W. M. van de Ven, and \\ Louk J. M. J. Vanderschuren \\ Drug Abuse Program, Research Institute Neurosciences Vrije Universiteit, Department of Medical Pharmacology, Vrije \\ Universiteit Medical Center, 1081 BT Amsterdam, The Netherlands
}

Animal studies have shown that nicotine and psychostimulant drugs (amphetamine and cocaine) share the property of inducing long-lasting behavioral and neurochemical sensitization, which is thought to contribute to their addictive properties. Neuroplasticity subserving learning and memory mechanisms is considered to be involved in psychostimulant-induced sensitization and addiction behavior. Because nicotinic receptors in the brain play a role in the storage of drug-related information underlying reinforcement learning, we evaluated the possibility that activation of central nicotinic receptors may underlie psychostimulant-induced sensitization. Repeated exposure of rats to nicotine profoundly enhanced the psychomotor effects of nicotine and amphetamine 3 weeks after nicotine pretreatment. Moreover, the nicotinic receptor antagonist mecamylamine completely blocked the induction, but not the long-term expression, of behavioral sensitization to amphetamine in amphetaminepretreated rats. Mecamylamine also prevented the development of cocaine-induced behavioral sensitization. Behavioral sensitization induced by nicotine, amphetamine, or cocaine was associated with an increase in the electrically evoked release of $\left[{ }^{3} \mathrm{H}\right] \mathrm{do}-$ pamine from nucleus accumbens slices. Coadministration of mecamylamine during pretreatment with nicotine, amphetamine, or cocaine prevented the development of this long-term hyperreactivity of nucleus accumbens dopamine neurons. Similarly, the high-affinity non- $\alpha 7$ subtype nicotinic receptor antagonist dihydro$\beta$-erythroidine prevented the development of amphetamineinduced behavioral and neurochemical sensitization. These data indicate that nicotinic receptor activation (by endogenously released acetylcholine) is a common denominator initiating neuroplasticity involved in the development of amphetamine, as well as cocaine-induced sensitization.

Key words: sensitization; nicotine; amphetamine; cocaine; nicotinic receptors; addiction; learning
Repeated exposure of rats to addictive drugs is well known to cause a long-lasting increase in their psychomotor and motivational effects (Stewart and Badiani, 1993; Jeziorski and White, 1995; Pierre and Vezina, 1997; Vanderschuren and Kalivas, 2000). This process of behavioral sensitization has been suggested to play a role in the acquisition and maintenance of addiction behavior (Robinson and Berridge, 1993; De Vries et al., 1998; Deroche et al., 1999). The long-lasting nature of behavioral sensitization may be attributable to persistently enhanced responsiveness of neurons that innervate the nucleus accumbens, such as dopamine neurons from the ventral tegmental area (VTA) and glutamate neurons from the prefrontal cortex and basolateral amygdala (for review, see Pierce and Kalivas, 1997; White and Kalivas, 1998; Vanderschuren and Kalivas, 2000). In this respect, recent evidence indicates that the neuroplasticity involved in long-term sensitization and drug addiction reflects an associative learning process (for review, see Berke and Hyman, 2000; Hyman and Malenka, 2001).

Activation of central nicotinic receptors acutely enhances dopamine and glutamate release in the nucleus accumbens (McGhee et al., 1995; Pontieri et al., 1996; Marshall et al., 1997; Wonnacott, 1997; Reid et al., 2000). It has also been shown to

\footnotetext{
Received Oct. 22, 2001; revised Jan. 7, 2002; accepted Feb. 6, 2002.

Correspondence should be addressed to Dr. Anton N. M. Schoffelmeer, Department of Medical Pharmacology, Vrije Universiteit Medical Center, Van der Boechorststraat 7, 1081 BT Amsterdam, The Netherlands. E-mail: anm.schoffelmeer. pharm@med.vu.nl.

Copyright () 2002 Society for Neuroscience $\quad 0270-6474 / 02 / 223269-08 \$ 15.00 / 0$
}

mediate the reinforcing effects of other drugs of abuse (Söderpalm et al., 2000; Zachariou et al., 2001). Moreover, repeated exposure to nicotine has been shown to cause behavioral sensitization associated with an enhanced reactivity of nucleus accumbens dopamine neurons (Benwell and Balfour, 1992; Reid et al., 1996; Iyaniwura et al., 2001; Shim et al., 2001), as well as crosssensitization to other addictive drugs (Horger et al., 1992; Birell and Balfour, 1998; Smith et al., 1999). However, other studies did not reveal such sensitizing effects shortly after repeated nicotine exposure (Schenk et al., 1991; Vezina et al., 1992; Nisell et al., 1996). These apparently discordant findings could be attributable to the time dependence of drug-induced sensitization, which strongly depends on the experimental conditions. For instance, psychostimulant and opiate-induced sensitization may involve a delayed form of neuroplasticity building up strength in time during drug withdrawal (Tjon et al., 1994; Vanderschuren et al., 1999; Schmidt et al., 2001).

Drugs of abuse acutely enhance the release of acetylcholine in the nucleus accumbens and related limbic brain areas and persistently increase the responsiveness of cholinergic neurons during repeated (Imperato et al., 1996; Bickerdike and Abercrombie, 1997; Nestby et al., 1997; Hedou et al., 2000; Nelson et al., 2000) and even single (Vanderschuren et al., 1999) drug exposure. Furthermore, central nicotinic receptors are considered to mediate storage of drug-related information underlying reinforcement learning (Changeux et al., 1998; Dani et al., 2001). Therefore, activation of brain nicotinic receptors may represent a common denominator involved in the process of sensitization induced by 
nicotine and other drugs of abuse. In the present study, this hypothesis was tested in rats by investigating the following: (1) the long-term effects of repeated nicotine exposure on amphetamine-induced locomotor activity and the reactivity of nucleus accumbens dopamine neurons, (2) the effect of nicotinic receptor antagonists on the development and long-term expression of behavioral sensitization after repeated amphetamine or cocaine administration, and (3) the effect of nicotine receptor blockade on the development of long-term hyperreactivity of nucleus accumbens dopamine neurons during repeated psychostimulant exposure.

\section{MATERIALS AND METHODS}

Animals and drug treatment. All experiments were approved by the Animal Care Committee of the Free University of Amsterdam. Male Wistar rats (Harlan CPB, Zeist, The Netherlands), weighing 140-160 gm at the time of arrival in the laboratory, were housed two per cage in Macrolon cages under controlled conditions (lights on from 7:00 A.M. to 7:00 P.M.). Animals were allowed to accustom to the housing conditions for at least 1 week before use. Food and water were available ad libitum. Animals were briefly handled on the $2 \mathrm{~d}$ preceding the beginning of pretreatment and on the $2 \mathrm{~d}$ preceding drug challenges. Pretreatment consisted of once daily intraperitoneal injections of amphetamine $(2.5$ $\mathrm{mg} / \mathrm{kg}, 5 \mathrm{~d})$, cocaine $(30 \mathrm{mg} / \mathrm{kg}, 5 \mathrm{~d})$, nicotine $(0.5 \mathrm{mg} / \mathrm{kg}, 5 \mathrm{~d})$, or saline $(1 \mathrm{ml} / \mathrm{kg}, 5 \mathrm{~d})$, administered in the home cage. Preliminary experiments revealed that repeated exposure of rats to these doses of the drugs (as used in previous studies on sensitization by our and other research groups) consistently induce long-lasting sensitization. The effects of nicotine receptor blockade on development of behavioral and neurochemical sensitization was studied by administering saline ( $1 \mathrm{ml} / \mathrm{kg}$, i.p.), mecamylamine (3 $\mathrm{mg} / \mathrm{kg}$, i.p.), or dihydro- $\beta$-erythroidine $(\mathrm{DH} \beta \mathrm{E})(2$ $\mathrm{mg} / \mathrm{kg}$, i.p.) $10 \mathrm{~min}$ before saline or psychostimulant administration. All drugs (salt weights) were dissolved in sterile saline. Injection volume was always $1 \mathrm{ml} / \mathrm{kg}$.

Determination of locomotor activity. Three weeks after the drug pretreatment period, horizontal motor activity was measured in Perspex cages $(40 \times 40 \times 35 \mathrm{~cm})$ using a video tracking system (EthoVision; Noldus Information Technology B.V., Wageningen, The Netherlands). This system determines the position of animals five times per second. Experiments were started at $\sim 9: 30$ A.M. White noise was used to minimize the influence of surrounding sounds. Locomotor challenge tests were conducted as follows. Animals were allowed to habituate to the test cages for $2 \mathrm{hr}$, during which activity was monitored. Then, animals received an injection with saline, and activity was monitored for $1 \mathrm{hr}$. Subsequently, animals were challenged with nicotine $(0.5 \mathrm{mg} / \mathrm{kg}$, i.p. $)$ or amphetamine $(0.5 \mathrm{mg} / \mathrm{kg}$, i.p.), and locomotor activity was monitored for $1 \mathrm{hr}$. In some experiments, mecamylamine $(3 \mathrm{mg} / \mathrm{kg}$, i.p.) or saline $(1$ $\mathrm{ml} / \mathrm{kg}$, i.p.) was injected $10 \mathrm{~min}$ before the amphetamine challenge. Animals were tested only once.

Determination of ex vivo neurotransmitter release. The occurrence of neurochemical sensitization was investigated in cohorts of rats distinct from those used to examine behavioral sensitization. Three weeks after saline or drug pretreatment, the nucleus accumbens of rats was rapidly dissected from coronal slices (bregma +1.2 to $+2.2 \mathrm{~mm}$ ) using the anterior commissure as reference point. Tissue slices $(0.3 \times 0.3 \times 1 \mathrm{~mm})$ were prepared using a McIlwain tissue chopper. Slices (pooled tissue of three rats) were washed twice with Krebs'-Ringer's bicarbonate medium (in mM: $121 \mathrm{NaCl}, 1.87 \mathrm{KCl}, 1.17 \mathrm{KH}_{2} \mathrm{PO}_{4}, 1.17 \mathrm{MgSO}_{4}, 1.22 \mathrm{CaCl}_{2}, 25$ $\mathrm{NaHCO}_{3}$, and $10 \mathrm{D}-(+)$-glucose) and subsequently incubated for $15 \mathrm{~min}$ in this medium under a constant atmosphere of $95 \% \mathrm{O}_{2}-5 \% \mathrm{CO}_{2}$ at $37^{\circ} \mathrm{C}$. After preincubation, the slices were rapidly washed with Krebs'Ringer's solution and incubated for $15 \mathrm{~min}$ in $2.5 \mathrm{ml}$ of this medium containing $5 \mu \mathrm{Ci}\left[{ }^{3} \mathrm{H}\right]$ dopamine under an atmosphere of $95 \% \mathrm{O}_{2}-5 \%$ $\mathrm{CO}_{2}$ at $37^{\circ} \mathrm{C}$. Because the nucleus accumbens has a dense noradrenergic innervation, $3 \mu \mathrm{M}$ desipramine was added to the medium during incubation of this brain region to prevent accumulation of $\left[{ }^{3} \mathrm{H}\right]$ dopamine in noradrenergic nerve terminals. After labeling, the slices were rapidly washed and transferred to each of 24 chambers of a superfusion apparatus ( $\sim 4 \mathrm{mg}$ of tissue in $0.2 \mathrm{ml}$ volume $)$ and superfused $(0.20 \mathrm{ml} / \mathrm{min})$ with medium gassed with $95 \% \mathrm{O}_{2}-5 \% \mathrm{CO}_{2}$ at $37^{\circ} \mathrm{C}$. In each experiment, neurotransmitter release from brain slices of saline- and drug-exposed rats was studied simultaneously in 24 parallel superfusion chambers. The superfusate was collected as $10 \mathrm{~min}$ samples after $40 \mathrm{~min}$ of superfusion $(t=40 \mathrm{~min})$. Calcium-dependent neurotransmitter release was induced during superfusion by exposing the slices to electrical biphasic block pulses ( $1 \mathrm{~Hz}, 30 \mathrm{~mA}, 4 \mathrm{msec}$ pulses) for $10 \mathrm{~min}$ at $t=50 \mathrm{~min}$ (electricalfield stimulation). After stimulation, two more $10 \mathrm{~min}$ samples were collected. The radioactivity remaining at the end of the experiment was extracted from the tissue with $0.1 \mathrm{~N} \mathrm{HCl}$. The radioactivity in superfusion fractions and tissue extracts was determined by liquid scintillation counting. The efflux of radioactivity during each collection period was expressed as a percentage of the amount of radioactivity in the slices at the beginning of the respective collection period (fractional release per superfusion chamber). The electrically evoked (exocytotic) release of $\left[{ }^{3} \mathrm{H}\right]$ dopamine was calculated by subtracting the spontaneous (nonvesicular) efflux of radioactivity from the total overflow of radioactivity during stimulation and the next $20 \mathrm{~min}$. A linear decline from the $10 \mathrm{~min}$ interval before that 20-30 min after the start of stimulation was assumed for calculation of the spontaneous efflux of radioactivity. The release evoked was expressed as percentage of the content of radioactivity of the slices at the start of the stimulation period.

Radiochemicals and drugs. [ $\left.{ }^{3} \mathrm{H}\right]$ Dopamine (specific activity, $47 \mathrm{Ci}$ / $\mathrm{mmol}$ ) was purchased from the Radiochemical Centre (Amersham Pharmacia Biotech, Buckinghamshire, UK). Desipramine, (-)nicotine ditartrate, $\mathrm{DH} \beta \mathrm{E}$, and mecamylamine hydrochloride were obtained from Sigma (St. Louis, MO). Cocaine hydrochloride and D- $(+)$ amphetamine sulfate were purchased from O.P.G. (Utrecht, The Netherlands).

Statistics. Horizontal locomotor activity, expressed as distance traveled (in centimeters) was calculated in $10 \mathrm{~min}$ blocks and as the total locomotor activity during the $1 \mathrm{hr}$ period after drug challenge. Statistical significance of differences $(p<0.05)$ was analyzed using ANOVA with repeated measures. Post hoc comparisons between experimental groups were made using one-way ANOVAs. Ex vivo neurotransmitter release from superfused nucleus accumbens slices, in excess of spontaneous efflux, was calculated as percentage of values observed in control groups (saline-saline and nicotinic receptor antagonist-saline-pretreated animals) in the respective experiments. Observations of different experiments were pooled and analyzed using one-way ANOVA.

\section{RESULTS}

None of the pretreatment regimens described below consistently altered locomotor activity during habituation to the test cages or after saline injections preceding drug challenges in the locomotor activity tests (indicated in the figures). Moreover, in the neurochemical experiments, none of the pretreatment regimens consistently altered the accumulation of $\left[{ }^{3} \mathrm{H}\right]$ dopamine in nucleus accumbens slices (data not shown).

\section{Nicotine-induced behavioral sensitization}

The locomotor effects of nicotine $(0.5 \mathrm{mg} / \mathrm{kg}$, i.p. $)$ and amphetamine $(0.5 \mathrm{mg} / \mathrm{kg}$, i.p.) in saline- and nicotine-pretreated rats are presented in Figure 1. Three weeks after repeated pretreatment with nicotine $(0.5 \mathrm{mg} / \mathrm{kg}$, i.p. $)$, the locomotor effect of nicotine in the nicotine-pretreated group of rats was significantly enhanced compared with that observed in the saline-pretreated group (Fig. $1 A$ ). Figure $1 B$ shows that nicotine pretreatment also caused a long-lasting increase in the locomotor effect of amphetamine, indicating that nicotine not only causes long-term behavioral sensitization but also cross-sensitization toward amphetamine under the present experimental conditions.

\section{Blockade of psychostimulant-induced behavioral sensitization by mecamylamine}

Preliminary experiments revealed that $3 \mathrm{mg} / \mathrm{kg}$ (intraperitoneally) of the nicotinic receptor antagonist mecamylamine caused maximal and complete blockade of the acute locomotor effect of $0.5 \mathrm{mg} / \mathrm{kg}$ nicotine, without affecting that of $0.5-2.5 \mathrm{mg} / \mathrm{kg}$ (intraperitoneally) amphetamine (data not shown). Therefore, this dose of mecamylamine was used in subsequent experiments to examine the possible role of nicotinic receptor activation in psychostimulant-induced long-term sensitization. As shown in Figure 2, repeated exposure to saline-amphetamine $(2.5 \mathrm{mg} / \mathrm{kg}$, 

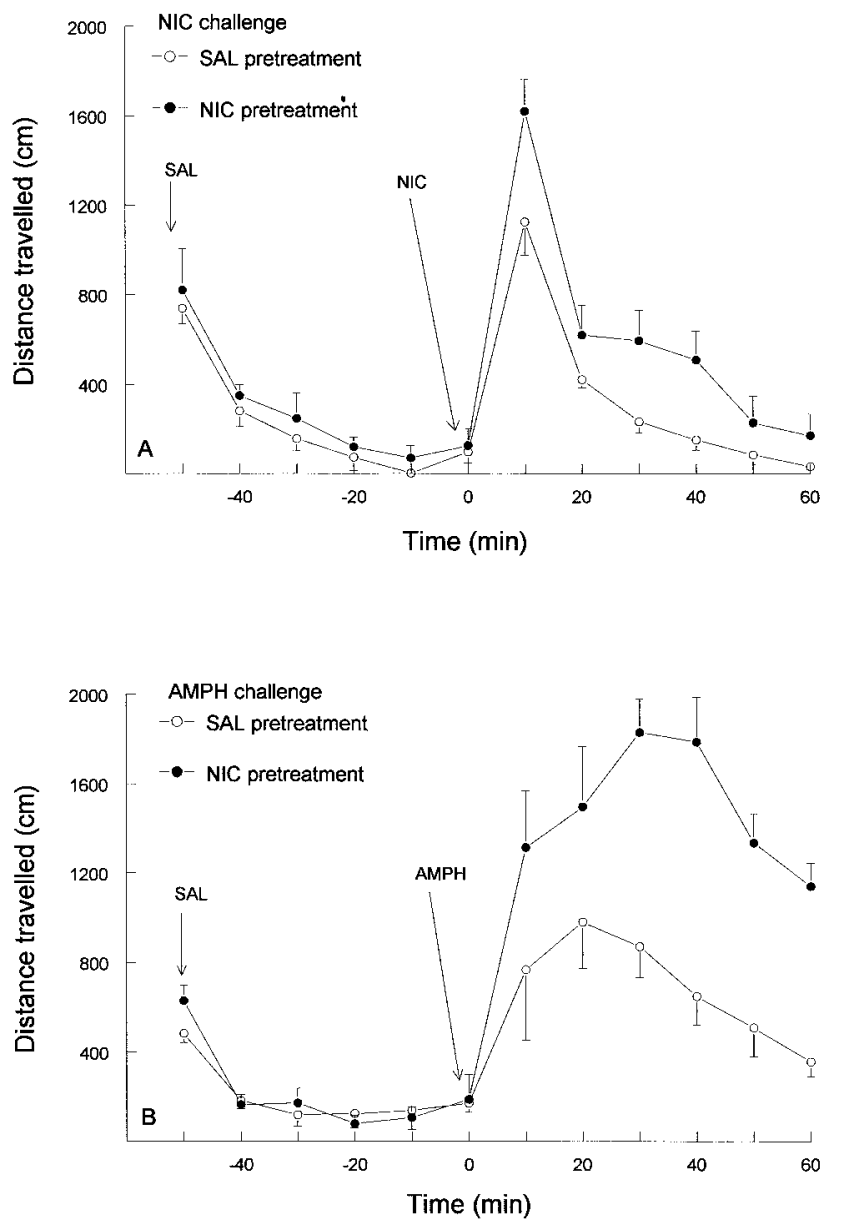

Figure 1. Nicotine-induced sensitization of nicotine- and amphetamineinduced locomotor activity. The locomotor responses to nicotine (NIC) $(A)$ and amphetamine $(A M P H)(B)$ were determined 3 weeks after repeated administration of saline $(S A L)$ or nicotine $(n=8$ for each group). Data are expressed as mean \pm SEM traveled distance (in centimeters) per $10 \mathrm{~min}$ interval. Total locomotor activity induced by nicotine and amphetamine challenge was significantly different in nicotine- versus saline-pretreated animals $\left(F_{(1,14)}=4.25, p<0.05 ; F_{(1,14)}=39.94, p<\right.$ $0.001)$.

i.p.) strongly enhanced the locomotor response to a challenge with amphetamine $(0.5 \mathrm{mg} / \mathrm{kg})$ compared with saline-salinepretreated rats. Amphetamine-induced locomotion in rats that received mecamylamine immediately $(10 \mathrm{~min})$ before the repeated saline injections did not differ from that observed in animals pretreated with saline only. When mecamylamine was coadministered with amphetamine during pretreatment, amphetamine-induced locomotor activity was strongly reduced compared with that in rats pretreated with saline-amphetamine. Accordingly, mecamylamine inhibited the development of longterm behavioral sensitization. In contrast, mecamylamine did not alter the long-term expression of amphetamine-induced locomotor sensitization, as shown in Figure 3. Thus, in amphetaminepretreated animals, amphetamine-induced locomotor activity was profoundly enhanced compared with locomotion in saline pretreated rats, independent of the presence of mecamylamine during the challenge with amphetamine. Blockade of the development of amphetamine-induced psychomotor sensitization by mecamylamine during pretreatment was also apparent when the amphetamine challenge was preceded by an injection of
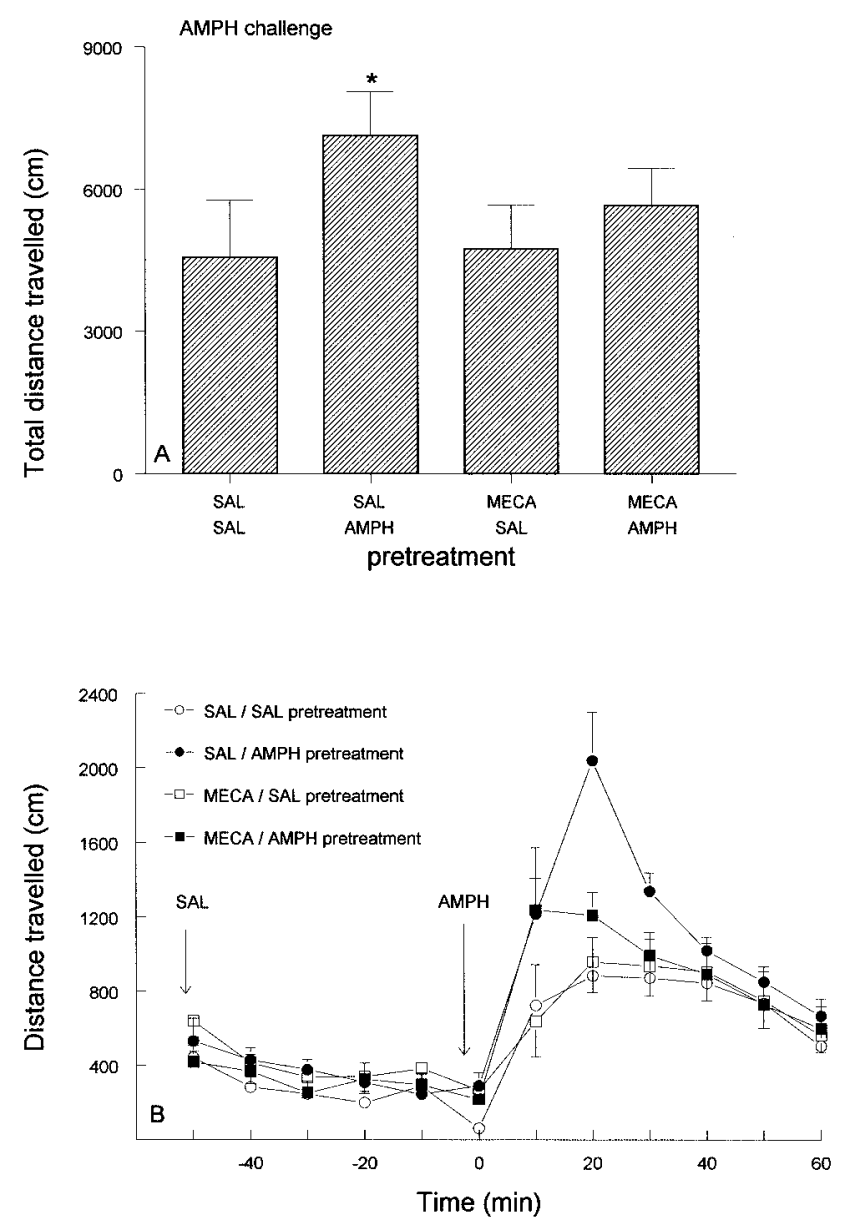

Figure 2. Blockade of the development of amphetamine-induced behavioral sensitization by mecamylamine. The locomotor responses to amphetamine $(A M P H)(n=11$ for each group) were determined 3 weeks after repeated administration of saline $(S A L)$-saline, saline-amphetamine, mecamylamine (MECA)-saline, or mecamylamine-amphetamine. Data are expressed as mean \pm SEM traveled distance (in centimeters) during the $1 \mathrm{hr}$ period after amphetamine challenge $(A)$, as well as per $10 \mathrm{~min}$ interval during this period $(B)$. Analysis of the results revealed a main effect of amphetamine pretreatment $\left(F_{(1,40)}=4.72, p<\right.$ $0.05)$, but not of mecamylamine pretreatment $\left(F_{(1,40)}=0.91\right.$, NS), and a significant interaction between the two $\left(F_{(1,40)}=4.31, p<0.05\right)$. * indicates different from saline-saline $\left(F_{(20)}=5.29, p<0.05\right)$ and mecamylamine-amphetamine $\left(F_{(, 20)}=4.05, p<0.05\right)$-pretreated rats.

mecamylamine, indicating that mecamylamine does not induce a state-dependent form of sensitization (Fig. 4).

Figure 5 shows that repeated pretreatment of rats with salinecocaine $(30 \mathrm{mg} / \mathrm{kg}$, i.p.) also caused a profound increase in the long-term locomotor effect of amphetamine compared with locomotor activity in saline-saline-pretreated animals. Moreover, whereas mecamylamine pretreatment did not alter amphetamineinduced locomotor activity, cocaine-induced long-term behavioral sensitization was completely prevented when the nicotinic receptor antagonist was injected $10 \mathrm{~min}$ before cocaine during pretreatment.

\section{Blockade of psychostimulant-induced neurochemical sensitization by mecamylamine}

Spontaneous (nonvesicular) tritium efflux from nucleus accumbens slices of saline-saline-pretreated rats amounted to $3.21 \pm$ $0.04 \%$ of total tissue radioactivity and was not altered by drug 

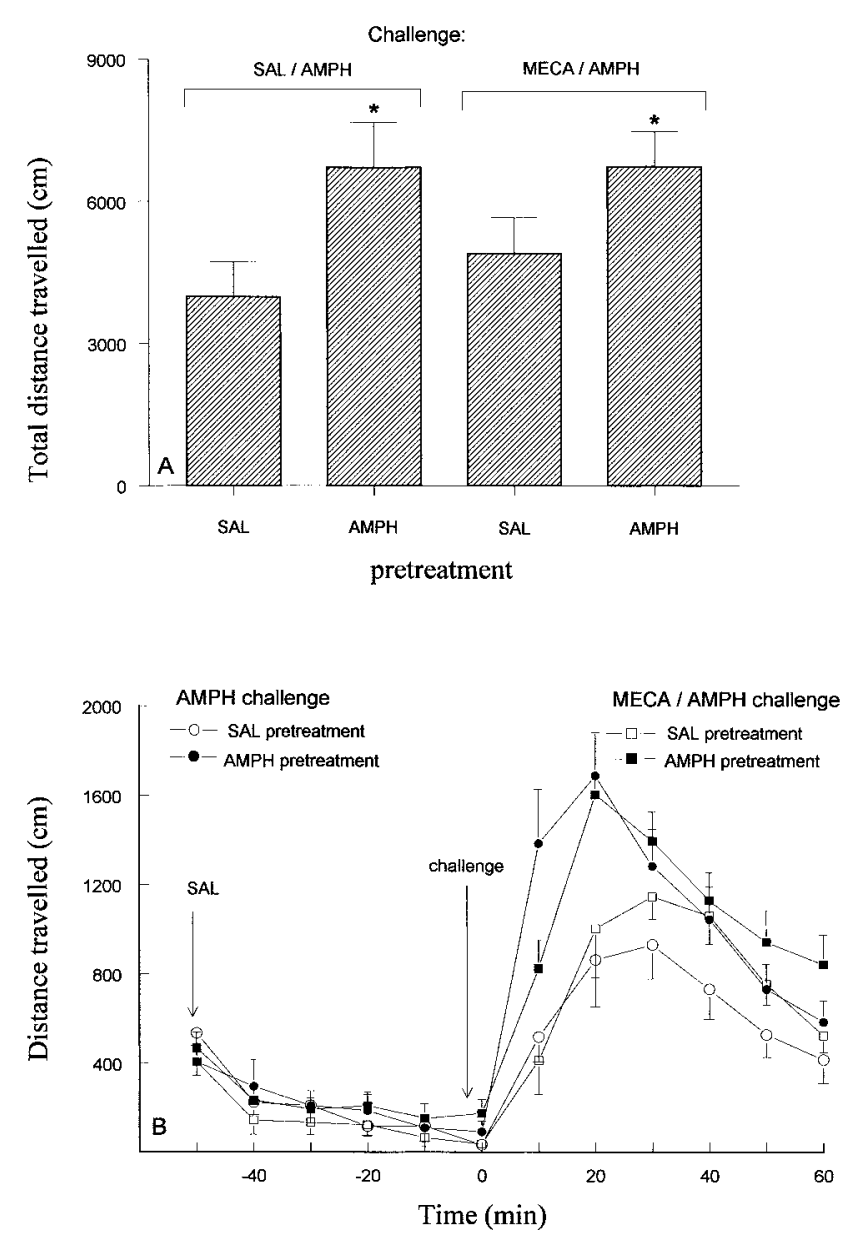

Figure 3. Expression of amphetamine-induced behavioral sensitization in the presence of mecamylamine. The locomotor responses to amphetamine $(A M P H)$ and mecamylamine $(M E C A)$ plus amphetamine $(n=14$ for each group) were determined 3 weeks after repeated administration of saline $(S A L)$ or amphetamine. Data are expressed as mean \pm SEM traveled distance (in centimeters) during the $1 \mathrm{hr}$ period after amphetamine with or without mecamylamine challenge $(A)$, as well as per $10 \mathrm{~min}$ interval $(B)$. Analysis of the results revealed a main effect of amphetamine pretreatment $\left(F_{(1,52)}=10.53, p<0.01\right)$ but not of drug challenge $\left(F_{(1,52)}=0.23, \mathrm{NS}\right)$ or an interaction between the two $\left(F_{(1,52)}=0.56, \mathrm{NS}\right)$. $*$ indicates different from saline-pretreated rats in the absence $\left(F_{(1,26)}=\right.$ $9.43, p<0.01)$ and presence $\left(F_{(1,26)}=5.22, p<0.05\right)$ of mecamylamine during amphetamine challenge.

pretreatment. The electrically evoked (exocytotic) release of $\left[{ }^{3} \mathrm{H}\right]$ dopamine from superfused nucleus accumbens slices of saline-saline-pretreated rats amounted to $1.35 \pm 0.12 \%$ of total tissue tritium, in excess of this spontaneous efflux. Repeated administration of saline-mecamylamine ( $3 \mathrm{mg} / \mathrm{kg}$, i.p.) did not affect this electrically evoked neurotransmitter release, amounting to $1.48 \pm 0.09 \%$ of total tissue tritium 3 weeks after drug administration. Figure 6 indicates that repeated administration of saline-nicotine, saline-amphetamine, or saline-cocaine caused an $\sim 50 \%$ increase in the electrically evoked $\left[{ }^{3} \mathrm{H}\right]$ dopamine release, 3 weeks after drug pretreatment, compared with neurotransmitter release from slices of saline-saline-pretreated animals. This long-term increase in the responsiveness of dopaminergic nerve terminals toward depolarization was no longer observed when mecamylamine was injected $10 \mathrm{~min}$ before the drugs of abuse during the pretreatment period.
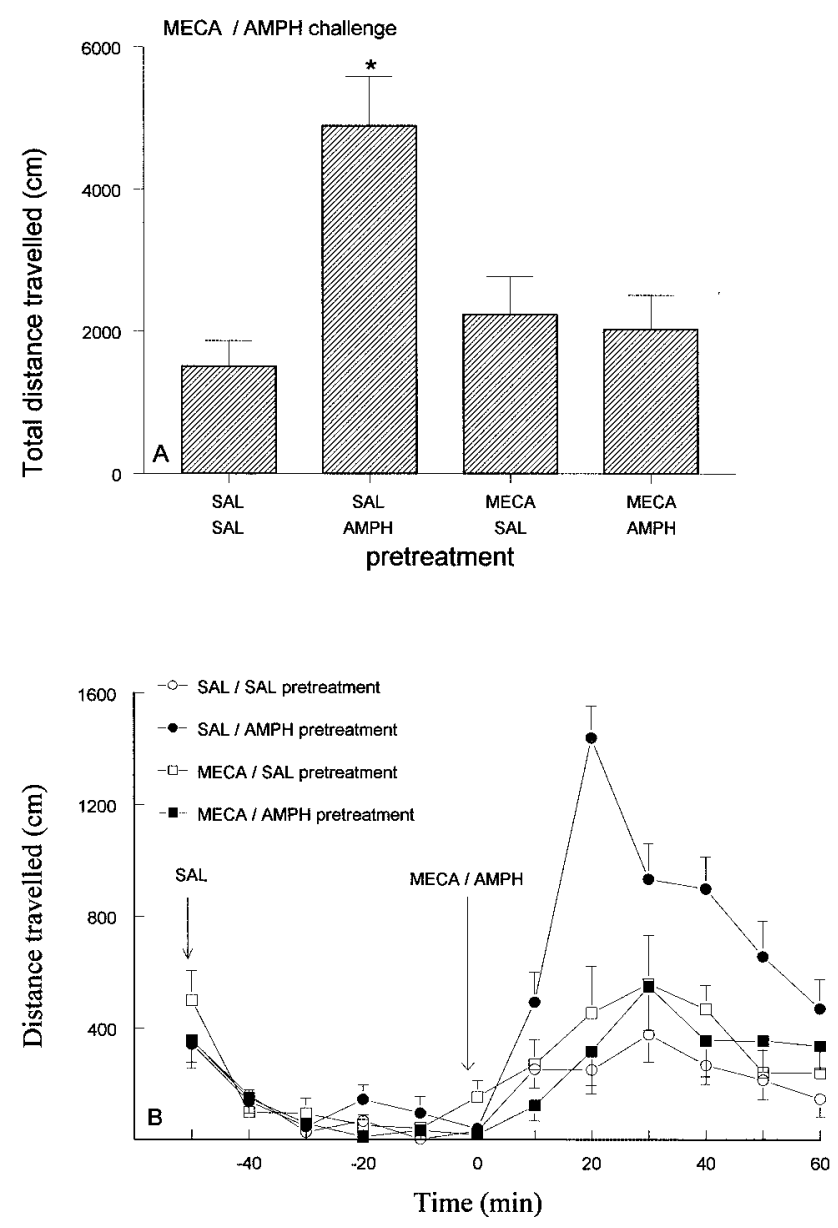

Figure 4. Blockade of the development of amphetamine-induced behavioral sensitization by mecamylamine during amphetamine challenge in the presence of the nicotinic receptor antagonist (state dependence). The locomotor responses to amphetamine $(A M P H)$ in the presence of mecamylamine (MECA) ( $n=8$ for each group) were determined 3 weeks after repeated administration of saline $(S A L)$-saline, saline-amphetamine, mecamylamine-saline, or mecamylamine-amphetamine. Data are expressed as mean \pm SEM traveled distance (in centimeters) during the $1 \mathrm{hr}$ period after amphetamine plus mecamylamine challenge $(A)$, as well as per $10 \mathrm{~min}$ interval $(B)$. Analysis of the results revealed a main effect of amphetamine pretreatment $\left(F_{(1,28)}=4.22, p<0.05\right)$, but not of mecamylamine $\left(F_{(1,28)}=0.24, \mathrm{NS}\right)$, and a significant interaction between the two $\left(F_{(1,28)}=10.23, p<0.01\right)$. * indicates different from saline-saline $\left(F_{(1,14)}=18.26, p<0.01\right)$ and mecamylamine-amphetamine $\left(F_{(1,14)}=\right.$ $16.91, p<0.01)$-pretreated rats.

\section{$\mathrm{DH} \beta \mathrm{E}$ mimics the effects of mecamylamine}

A dose of $2 \mathrm{mg} / \mathrm{kg} \mathrm{DH} \beta \mathrm{E}$ (intraperitoneally) appeared to cause maximal and complete inhibition of the locomotor effect of 0.5 $\mathrm{mg} / \mathrm{kg}$ (intraperitoneally) nicotine, without affecting that of $0.5-$ $2.5 \mathrm{mg} / \mathrm{kg}$ (intraperitoneally) amphetamine (data not shown). Therefore, this dose of the nicotinic receptor antagonist was used in subsequent experiments. As shown in Figure 7, repeated administration of saline-amphetamine strongly enhanced the locomotor effect of amphetamine 3 weeks later compared with its locomotor effect in saline-saline-pretreated animals. Whereas repeated pretreatment with $\mathrm{DH} \beta \mathrm{E}$-saline did not alter amphetamine-induced locomotor activity, the nicotinic receptor antagonist, when administered 10 min before amphetamine during pretreatment, completely prevented the occurrence long-term behavioral sensitization (Fig. 7). 

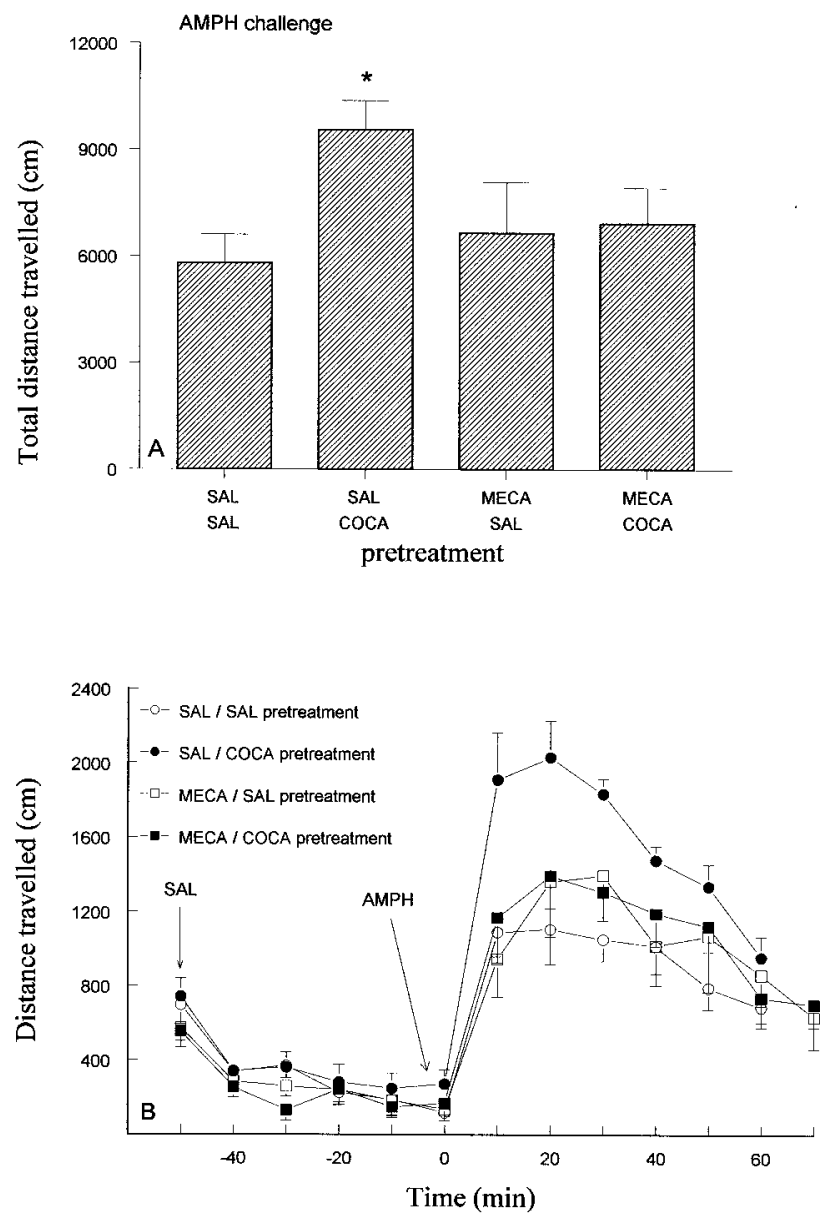

Figure 5. Blockade of the development of cocaine-induced behavioral sensitization by mecamylamine. The locomotor responses to amphetamine $(A M P H)$ ( $n=14$ for each group) were determined 3 weeks after repeated administration of saline $(S A L)$-saline, saline-cocaine $(C O C A)$, mecamylamine $(M E C A)$-saline, or mecamylamine-cocaine. Data are expressed as mean \pm SEM traveled distance (in centimeters) during the $1 \mathrm{hr}$ period after amphetamine challenge $(A)$, as well as per $10 \mathrm{~min}$ interval $(B)$. Analysis of the results revealed no main effect of cocaine $\left(F_{(1,52)}=2.96, p<0.05\right)$ and mecamylamine $\left(F_{(1,52)}=0.63, \mathrm{NS}\right)$ pretreatment and a significant interaction between the two $\left(F_{(1,52)}=4.85, p<\right.$ $0.05) .{ }^{*}$ indicates different from saline-saline $\left(F_{(1,26)}=14.69, p<0.01\right)$ and mecamylamine-saline $\left(F_{(1,26)}=7.42, p<0.01\right)$-pretreated rats.

In the experiments studying the effect of $\mathrm{DH} \beta \mathrm{E}$ on the development of amphetamine-induced neurochemical sensitization, spontaneous tritium efflux from nucleus accumbens slices of saline-saline-pretreated rats amounted to $3.01 \pm 0.12 \%$ of total tissue radioactivity and was not altered by repeated administration of amphetamine or $\mathrm{DH} \beta \mathrm{E}$. The electrically evoked release of $\left[{ }^{3} \mathrm{H}\right]$ dopamine in excess of spontaneous tritium efflux from slices of saline-saline-pretreated rats amounted to $1.43 \pm 0.14 \%$ of total tissue tritium. The electrically evoked neurotransmitter release was not affected by repeated $\mathrm{DH} \beta \mathrm{E}$ exposure, amounting to $1.50 \pm 0.13 \%$ in $\mathrm{DH} \beta \mathrm{E}-$ saline-pretreated animals. Figure 8 indicates that repeated administration of saline-amphetamine enhanced the electrically evoked release of $\left[{ }^{3} \mathrm{H}\right]$ dopamine by $\sim 50 \%$ compared with that observed in slices from saline-salinepretreated rats. In contrast, the electrically evoked neurotransmitter release from nucleus accumbens slices of $\mathrm{DH} \beta \mathrm{E}-$ amphetamine-pretreated rats was not different from that of

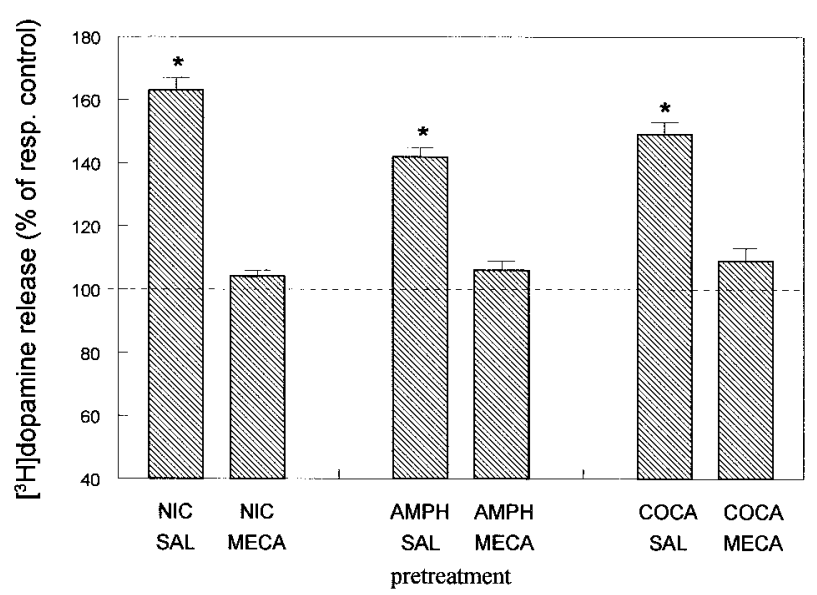

Figure 6. Blockade of the development of nicotine-, amphetamine-, and cocaine-induced neurochemical sensitization by mecamylamine. The electrically evoked release of $\left[{ }^{3} \mathrm{H}\right]$ dopamine from superfused nucleus accumbens slices was determined 3 weeks after repeated administration of saline $(S A L)$-saline, mecamylamine $(M E C A)$-saline, saline-drug of abuse (nicotine, NIC; amphetamine, $A M P H$; cocaine, COCA), or mecamylamine-drug of abuse. Data are expressed as percentage of the evoked neurotransmitter release from nucleus accumbens slices of control (saline-saline- or mecamylamine-saline-pretreated) animals (which did not differ). In each of the nicotine, amphetamine, and cocaine experiments, these separate control groups were included. Data represent means \pm SEM of 24 observations. * indicates different from respective control values (nicotine, $F_{(1,46)}=36.32, p<0.001$; amphetamine, $F_{(1,46)}=$ 17.46, $p<0.01$; cocaine, $\left.F_{(1,46)}=19.21, p<0.01\right)$.

observed from nucleus accumbens slices of $\mathrm{DH} \beta \mathrm{E}$-salinepretreated animals.

\section{DISCUSSION}

Dopamine and glutamate neurotransmission in the mesocorticolimbic system is critically involved in the development and expression of drug-induced behavioral sensitization (Pierce and Kalivas, 1997; Vanderschuren and Kalivas, 2000). The brain regions involved in this long-lasting behavioral effect of drugs of abuse have been studied in most detail for amphetamine- and cocaine-induced sensitization. The VTA, giving rise to nucleus accumbens dopamine neurons, and the medial prefrontal cortex and amygdala, providing glutamate input to the VTA and nucleus accumbens, are thought to be primarily involved in the induction of behavioral sensitization. The long-term expression of psychostimulant-induced behavioral sensitization may particularly involve persistent changes in dopamine and glutamate neurotransmission within the nucleus accumbens (Vanderschuren and Kalivas, 2000). However, the contribution of these neuronal systems may differ regarding the long-term sensitizing effects of amphetamine and cocaine (White and Kalivas, 1998).

Little is known regarding the role of nicotinic receptors in psychostimulant-induced behavioral and neurochemical sensitization. Neurochemical and neurophysiological studies indicated that activation of nicotinic receptors increases the activity of distinct neurons throughout the brain, including mesocorticolimbic dopamine and glutamate neurons (McGhee et al., 1995; Pontieri et al., 1996; Marshall et al., 1997; Wonnacott, 1997; Reid et al., 2000). Because exposure of rats to psychostimulants has been shown to acutely enhance acetylcholine release in various limbic brain regions and persistently increases the reactivity of cholinergic neurons (Bickerdike and Abercrombie, 1997; Nestby et al., 1997; Hedou et al., 2000; Nelson et al., 2000), it is conceivable that 

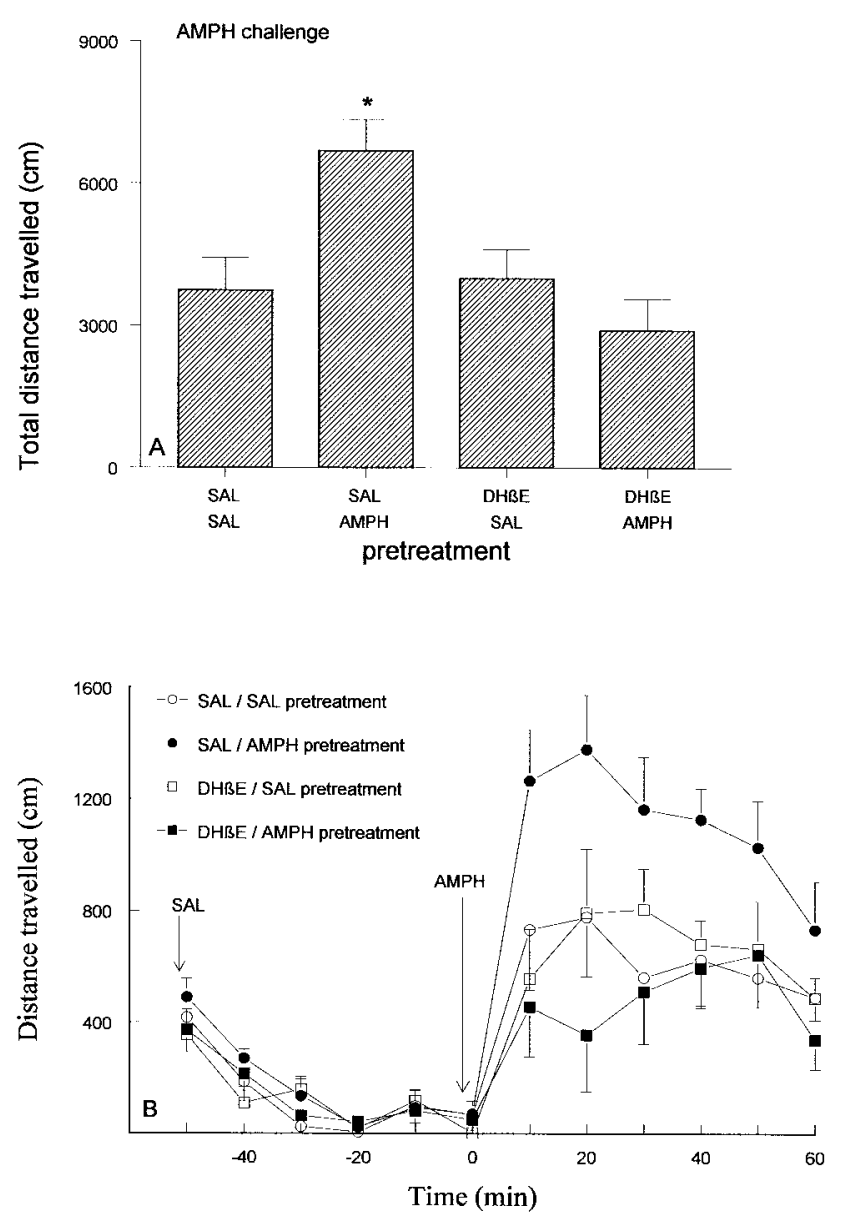

Figure 7. Blockade of the development of amphetamine-induced behavioral sensitization by $\mathrm{DH} \beta \mathrm{E}$. The locomotor responses to amphetamine $(A M P H)(n=14$ per group) were determined 3 weeks after repeated administration of saline $(S A L)$-saline, saline-amphetamine, $\mathrm{DH} \beta \mathrm{E}-$ saline, or $\mathrm{DH} \beta \mathrm{E}-$ amphetamine. Data are expressed as mean $\pm \mathrm{SEM}$ traveled distance (in centimeters) during the $1 \mathrm{hr}$ period after amphetamine challenge $(A)$, as well as per $10 \mathrm{~min}$ interval $(B)$. Analysis of the results revealed no main effect of amphetamine $\left(F_{(, 52)}=2.97\right.$, NS) or $\operatorname{DH} \beta \mathrm{E}\left(F_{(1,52)}=0.20, \mathrm{NS}\right)$ pretreatment and a significant interaction between the two $\left(F_{(1,52)}=9.53, p<0.01\right)$. ${ }^{*}$ indicates different from saline-saline $\left(F_{(1,26)}=10.28, p<0.01\right)$ and $\mathrm{DH} \beta \mathrm{E}$-amphetamine $\left(F_{(, 26)}=12.87, p<0.01\right)$-pretreated rats.

nicotinic receptor activation by released acetylcholine may be involved in the induction and/or expression of behavioral and neurochemical sensitization during repeated exposure to drugs of abuse, such as amphetamine or cocaine.

Our present data strongly suggest that this may indeed be the case considering the development, but not the long-term expression, of psychostimulant-induced sensitization. Accordingly, repeated administration of nicotine not only enhanced the psychomotor effect of nicotine but also strongly increased that of amphetamine. Moreover, previous nicotine exposure enhanced the electrically evoked release of $\left[{ }^{3} \mathrm{H}\right]$ dopamine from superfused nucleus accumbens slices, indicating the occurrence of a longlasting hyperreactivity of dopaminergic nerve terminals toward depolarization, as observed during pretreatment of rats with amphetamine and cocaine. Most importantly, when the nicotinic receptor antagonist mecamylamine was administered together with amphetamine or cocaine during pretreatment, the development of long-term behavioral sensitization was prevented. Block-

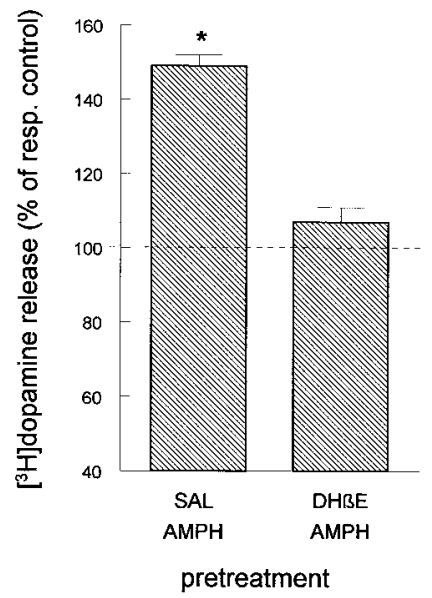

Figure 8. Blockade of the development of amphetamine-induced neurochemical sensitization by $\mathrm{DH} \beta \mathrm{E}$. The electrically evoked release of $\left[{ }^{3} \mathrm{H}\right]$ dopamine from superf used nucleus accumbens slices was determined 3 weeks after repeated administration of saline $(S A L)$-saline, DH $\beta \mathrm{E}-$ saline, saline-amphetamine $(A M P H)$, or $\mathrm{DH} \beta \mathrm{E}$-amphetamine. Data are expressed as percentage of the evoked neurotransmitter release from nucleus accumbens slices of control (saline-saline- or DH $\beta E$-salinepretreated) animals (which did not differ). Data represent means \pm SEM of 18 observations. ${ }^{*}$ indicates different from control values $\left(F_{(1,34)}=\right.$ 26.86, $p<0.001)$.

ade of psychostimulant-induced psychomotor sensitization was still apparent when rats received an injection of mecamylamine immediately before the amphetamine challenge in the psychomotor activity test. This indicates that mecamylamine indeed prevented the development of behavioral sensitization rather than inducing a state-dependent form of sensitization as, for example, observed for the NMDA receptor antagonist MK-801 [(+)-5methyl-10,11-dihydro-5H-dibenzo [a,d] cyclohepten-5,10-imine maleate] (Wise et al., 1996). Mecamylamine also prevented the development of long-term hyperreactivity of dopamine neurons toward depolarization in nucleus accumbens slices of nicotine-, amphetamine-, or cocaine-pretreated rats. Thus, mecamylamine appears to prevent the induction of behavioral sensitization, as well as the development of neurochemical sensitization of mesolimbic dopamine neurons. On the other hand, when amphetaminepretreated rats were challenged with amphetamine in the presence of mecamylamine, behavioral sensitization was not changed, indicating that the nicotinic receptor antagonist does not block the long-term expression of psychomotor sensitization. The nicotinic receptor antagonist $\mathrm{DH} \beta \mathrm{E}$ mimicked the effect of mecamylamine on the development of amphetamine-induced psychomotor and neurochemical sensitization. This is of importance given the evidence that mecamylamine may also block NMDA receptors, albeit at very high concentrations (Snell and Johnson, 1989). Moreover, because $\mathrm{DH} \beta \mathrm{E}$ is a selective antagonist for nicotinic receptors other than homomeric $\alpha 7$ receptors, our data suggest that non- $\alpha 7$ nicotinic receptors may be involved in psychostimulant-induced sensitization, as shown for the acute psychomotor and reinforcing effects of nicotine (Picciotto et al., 1998; Grottick et al., 2000).

The elucidation of the neuroanatomical localization of the nicotinic receptors involved in the induction of long-term psychomotor sensitization is beyond the scope of the current study and requires behavioral studies after microinjections of nicotinic receptor (ant)agonists in subregions of the nucleus accumbens and functionally connected mesocorticolimbic brain areas. Because our data indicate that the development, but not the expres- 
sion, of psychostimulant sensitization depends on nicotinic receptor activation, and the nucleus accumbens is primarily involved in the expression rather than in the development of behavioral sensitization (Vanderschuren and Kalivas, 2000), it appears most likely that these nicotinic receptors do not reside in the nucleus accumbens. However, injections of nicotine in rat nucleus accumbens was shown to produce sensitization to the psychomotor effect of nicotine (Kitay et al., 1992), and amphetamine-induced (short-term) sensitization to stereotypy in mice appeared to be attenuated by intrastriatal application of nicotinic receptor antagonists (Karler et al., 1996). Therefore, a role for nucleus accumbens nicotinic receptors in the development of sensitization cannot be ruled out.

Recent behavioral studies indicate that the process of sensitization that occurs during repeated exposure to drugs of abuse may be one of the key factors involved in the acquisition and maintenance of compulsive drug-seeking behavior (De Vries et al., 1998; Deroche et al., 1999; De Vries et al., 1999). Therefore, the present study may also be of importance for our understanding of the molecular and cellular basis of drug addiction. Thus, although repeated activation of nicotinic receptors by nicotine may result in nicotine addiction in vulnerable individuals, their activation by released acetylcholine during amphetamine or cocaine consumption might contribute to the development of drug abuse. Accordingly, previous nicotine exposure appeared to enhance the acquisition of intravenous cocaine self-administration in rats (Horger et al., 1992), and nicotinic receptor inactivation has been shown to attenuate the reinforcing effect of cocaine (Zachariou et al., 2001).

The importance of intermittent (rather than sustained) drug exposure in the development of neurochemical (Tjon et al., 1994) and behavioral (Vanderschuren et al., 1997) sensitization and the persistence of sensitization and drug addiction long after cessation of drug exposure displays striking similarities with an associative learning process by which the brain stores specific patterns of drug-related information. Therefore, the development of behavioral sensitization and addiction behavior is thought to be attributable to long-term alterations in neuronal gene expression in the mesocorticolimbic system, involving synaptic processes that mediate learning and long-term memory formation. In this respect, it is of interest to note that psychostimulant exposure may even facilitate learning of specific behaviors that are unrelated to drug intake (Berke and Hyman, 2000; Hyman and Malenka, 2001). Reinforcement learning depends on the coordinated activity of mesocorticolimbic neurons, with a particular important role for dopamine and glutamate neurotransmission in the nucleus accumbens (Kelley, 1999; Parkinson et al., 1999). There is strong evidence that nicotine administration, as well as psychostimulant exposure, may enhance this dopamine and glutamate transmission and that psychostimulant administration may cause activation of central nicotinic receptors by enhancing acetylcholine release (see above). Moreover, nicotinic receptor activation is a common denominator underlying the development of amphetamine- and cocaine-induced sensitization (present study), and activation of nicotinic receptors is considered to mediate reinforcement learning (Changeux et al., 1998; Dani et al., 2001). Therefore, we tentatively suggest that the development of amphetamine, as well as cocaine-induced long-term sensitization, is attributable to neuroplasticity subserving a learning and memory process that is triggered by activation of nicotinic receptors in the mesocorticolimbic system.

\section{REFERENCES}

Benwell MEM, Balfour DJK (1992) The effects of acute and repeated nicotine treatment on nucleus accumbens dopamine and locomotor activity. Br J Pharmacol 105:849-856.

Berke JD, Hyman SE (2000) Addiction, dopamine, and the molecular mechanisms of memory. Neuron 25:515-532.

Bickerdike MJ, Abercrombie ED (1997) Striatal acetylcholine release correlates with behavioral sensitization in rats withdrawn from chronic amphetamine. J Pharmacol Exp Ther 282:818-826.

Birell CE, Balfour DJK (1998) The influence of nicotine pretreatment on mesoaccumbens dopamine overflow and locomotor responses to $d$-amphetamine. Psychopharmacology 140:142-149.

Changeux J-P, Bertrand D, Corringer P-J, Dehaene S, Edelstein S, Léna C, Le Novère N, Marubio L, Picciotto M, Zoli M (1998) Brain nicotinic receptors: structure and regulation, role in learning and reinforcement. Brain Res Rev 26:198-216.

Dani JA, Ji D, Zhou F-M (2001) Synaptic plasticity and nicotine addiction. Neuron 31:349-352.

Deroche V, Le Moal M, Piazza PV (1999) Cocaine self-administration increases the incentive motivational properties of the drug in rats. Eur J Neurosci 11:2731-2736.

De Vries TJ, Schoffelmeer ANM, Binnekade R, Mulder AH, Vanderschuren LJMJ (1998) Drug-induced reinstatement of heroin- and cocaine-seeking behaviour after long-term extinction is associated with expression of behavioural sensitization. Eur J Neurosci 10:3565-3571.

De Vries TJ, Schoffelmeer ANM, Binnekade R, Vanderschuren LJMJ (1999) Dopaminergic mechanisms mediating the incentive to seek cocaine and heroin following long-term withdrawal of i.v. drug selfadministration. Psychopharmacology 143:254-260.

Grottick AJ, Trube G, Corrigall WA, Huwyler J, Malherbe P, Wyler R, Higgins GA (2000) Evidence that nicotinic $\alpha 7$ receptors are not involved in the hyperlocomotor and rewarding effects of nicotine. J Pharmacol Exp Ther 294:1112-1119.

Hedou G, Homberg J, Martin S, Wirth K, Feldon J, Heidbreder CA (2000) Effect of amphetamine on extracellular acetylcholine and monoamine levels in subterritories of the rat medial prefrontal cortex. Eur J Pharmacol 390:127-136.

Horger BA, Giles MK, Schenk S (1992) Preexposure to amphetamine and nicotine predisposes rats to self-administer a low dose of cocaine. Psychopharmacology 107:271-276.

Hyman SE, Malenka RC (2001) Addiction and the brain: the neurobiology of compulsion and its persistence. Nat Med 2:695-703.

Imperato A, Obinu MC, Casu MA, Mascia MS, Carta G, Gessa GL (1996) Chronic morphine increase hippocampal acetylcholine release: possible relevance in drug dependence. Eur J Pharmacol 302:21-26.

Iyaniwura TT, Wright AE, Balfour DJK (2001) Evidence that mesoaccumbens dopamine and locomotor responses to nicotine in the rat are influenced by pre-treatment dose and strain. Psychopharmacology 158:73-79.

Jeziorski M, White FJ (1995) Dopamine receptor antagonists prevent expression, but not development, of morphine sensitization. Eur J Pharmacol 275:235-244.

Karler R, Calder LD, Bedingfield JB (1996) A novel nicotiniccholinergic role in behavioral sensitization to amphetamine-induced stereotypy in mice. Brain Res 725:192-198.

Kelley AE (1999) Neural integrative activities of nucleus accumbens subregions in relation to learning and motivation. Psychobiology 27:198-211.

Kitay T, Okamoto M, Nakashima T (1992) Nicotine-induced sensitization to the ambulatory stimulant effect produced by daily administration into the ventral tegmental area and the nucleus accumbens in rats. Life Sci 50:583-590.

Marshall DL, Redfern PH, Wonnacott S (1997) Presynaptic nicotinic modulation of dopamine release in the three descending pathways studied by in vivo microdialysis: comparison of naive and chronic nicotine-treated rats. J Neurochem 68:1511-1519.

McGhee DS, Heath MJS, Gelber S, Devay P, Role LW (1995) Nicotine enhancement of fast excitatory synaptic transmission in CNS by presynaptic receptors. Science 269:1692-1696.

Nelson CL, Sarter M, Bruno JP (2000) Repeated pretreatment with amphetamine sensitizes increases in cortical acetylcholine release. Psychopharmacology 151:406-415.

Nestby P, Vanderschuren LJMJ, De Vries TJ, Hogenboom F, Wardeh G, Mulder AH, Schoffelmeer ANM (1997) Ethanol, like psychostimulants and morphine, causes long-lasting hyperreactivity of dopamine and acetylcholine neurons of rat nucleus accumbens: possible role in behavioural sensitization. Psychopharmacology 133:69-76.

Nisell M, Nomikos GG, Hertel P, Panagis G, Svensson TH (1996) Condition-dependent sensitization of locomotor stimulation and mesocortical dopamine release following chronic nicotine treatment in the rat. Synapse 22:369-381.

Parkinson JA, Olmstead MC, Burns LH, Robbins TW, Everitt BJ (1999) Dissociation in effects of lesions of the nucleus accumbens core and shell on appetitive Pavlovian approach behavior and the potentiation of 
conditioned reinforcement and locomotor activity by d-amphetamine. J Neurosci 19:2401-2411.

Picciotto MR, Zoli M, Rimondini R, Léna C, Marubio LM, Pich EM, Fuxe K, Changeux J-P (1998) Acetylcholine receptors containing the $\beta 2$ subunit are involved in the reinforcing properties of nicotine. Nature 391:173-177.

Pierce RC, Kalivas PW (1997) A circuitry model of the expression of behavioral sensitization to amphetamine-like psychostimulants. Brain Res Rev 25:192-216.

Pierre PJ, Vezina P (1997) Predisposition to self-administer amphetamine: the contribution of response to novelty and prior exposure to the drug. Psychopharmacology 129:277-284.

Pontieri FE, Tanda G, Orzi F, Di Chiara G (1996) Effects of nicotine on the nucleus accumbens and similarity to those of addictive drugs. Nature 382:255-257.

Reid MS, Ho LB, Berger SP (1996) Effects of environmental conditioning on the development of nicotine sensitization: behavioral and neurochemical analysis. Psychopharmacology 126:301-310.

Reid MS, Fox L, Ho LB, Berger SP (2000) Nicotine stimulation of extracellular glutamate levels in the nucleus accumbens: neuropharmacological characterization. Synapse 35:129-136.

Robinson TE, Berridge KC (1993) The neural basis of drug craving: an incentive sensitization theory of addiction. Brain Res Rev 18:247-291.

Schenk S, Snow S, Horger BA (1991) Pre-exposure to amphetamine but not to nicotine sensitises rats to the motor activating effect of cocaine. Psychopharmacology 103:62-66.

Schmidt ED, Schoffelmeer ANM, De Vries TJ, Wardeh G, Dogterom G, Bol JGJM, Binnekade R, Tilders FJH (2001) A single administration of interleukin-1 or amphetamine induces long-lasting increases in evoked noradrenaline release in the hypothalamus and sensitization of $\mathrm{ACTH}$ and corticosterone responses in rats. Eur J Neurosci 13:1923-1930.

Shim I, Javaid JI, Wirtshafter D, Jang SY, Shim KH, Lee HJ, Chung YC, Chung BG (2001) Nicotine-induced behavioral sensitization is associated with extracellular dopamine release and expression of c-fos in the striatum and nucleus accumbens of the rat. Behav Brain Res 121:137-147.

Smith BR, Horan JT, Gaskin S, Amir Z (1999) Exposure to nicotine enhances acquisition of ethanol drinking by laboratory rats in a limited access paradigm. Psychopharmacology 142:408-412.

Snell LD, Johnson KM (1989) Effects of nicotinic agonists and antago- nists on $N$-methyl-D-aspartate-induced ${ }^{3} \mathrm{H}$-norepinephrine release and ${ }^{3} \mathrm{H}(1-[1-(2$-thienyl)-cyclohexyl]-piperidine) binding in rat hippocampus. Synapse 3:129-137.

Söderpalm B, Ericson M, Olausson P, Blomqvist O, Engel JA (2000) Nicotinic mechanisms involved in the dopamine activating and reinforcing properties of ethanol. Behav Brain Res 113:85-96.

Stewart J, Badiani A (1993) Tolerance and sensitization to the behavioral effects of drugs. Behav Pharmacol 4:289-312.

Tjon GHK, De Vries TJ, Ronken E, Hogenboom F, Wardeh G, Mulder AH, Schoffelmeer ANM (1994) Repeated and chronic morphine administration causes differential long-lasting changes in dopaminergic neurotransmission in rat striatum without changing its delta- and kappa-opioid receptor regulation. Eur J Pharmacol 252:205-212.

Vanderschuren LJMJ, Kalivas PW (2000) Alterations in dopaminergic and glutamatergic transmission in the induction and expression of behavioral sensitization: a critical review of preclinical studies. Psychopharmacology 151:99-120.

Vanderschuren LJMJ, Tjon GHK, Nestby P, Mulder AH, Schoffelmeer ANM, DE Vries TJ (1997) Morphine-induced long-term sensitization to the locomotor effects of morphine and amphetamine depends on the temporal pattern of the pretreatment regimen. Psychopharmacology 131:115-122

Vanderschuren LJMJ, Schmidt ED, De Vries TJ, Van Moorsel CAP, Tilders FJH, Schoffelmeer ANM (1999) A single exposure to amphetamine is sufficient to induce long-term behavioral, neuroendocrine and neurochemical sensitization in rats. J Neurosci 19:9579-9586.

Vezina P, Blanc G, Glowinski J, Tassin J-P (1992) Nicotine and morphine differentially activate brain dopamine in prefrontocortical and subcortical terminal fields: effects of acute and repeated injections. J Pharmacol Exp Ther 261:484-490.

White FJ, Kalivas PW (1998) Neuroadaptations involved in amphetamine and cocaine addiction. Drug Alcohol Depend 51:141-153.

Wise RA, Mendrek A, Carlezon WA (1996) MK-801 (dizocilpine): Synergistic and conditioned stimulus in bromocryptine-induced psychomotor sensitization. Synapse 22:362-368.

Wonnacott S (1997) Presynaptic nicotinic ACh receptors. Trends Neurosci 20:92-98.

Zachariou V, Caldarone BJ, Weathers-Lowin A, George TP, Elsworth JD, Roth RH, Changeux J-P, Picciotto MR (2001) Nicotine receptor inactivation decreases sensitivity to cocaine. Neuropsychopharmacology 24:576-589. 